\title{
Multidimensional Nano-HPLC for Analysis of Protein Complexes
}

\author{
Yvonne Wagner and Albert Sickmann \\ Rudolf Virchow-Zentrum, Julius Maximilians University Wuerzberg, Wuerzburg, Germany \\ Helmut E. Meyer \\ Medical Proteom-Center, Ruhr University of Bochum, Bochum, Germany \\ Günther Daum \\ Institute of Biochemistry, Graz University of Technology, Graz, Austria
}

\begin{abstract}
The analysis of macromolecular protein complexes is an important factor in understanding most cellular processes, e.g., protein transport into cell organells, signal transduction via biological membranes, apoptosis, energy metabolism, directed motion of cells, and cell division. These complexes are not only built of various numbers of different proteins but also of prosthetic groups and RNA molecules. To understand the role each protein plays in a complex, a complete analysis of all protein compounds is necessary. Therefore, several separation steps have to be coupled to mass spectrometry to identify the proteins. In this work, we describe the application of multidimensional liquid chromatography, SCX-RP-LC as well as SAX-RP-LC, coupled to electrospray ion trap mass spectrometry. Tryptic digested ribosomes were separated by ion exchange chromatography manually collected and prepared for reversed phase chromatography to analyze the peptides via nano-ESI mass spectrometry. The total numbers of identified proteins are compared in consideration of the separation method (SCX-RP versus SAX-RP). (J Am Soc Mass Spectrom 2003, 14, 1003-1011) (C 2003 American Society for Mass Spectrometry
\end{abstract}

$\mathrm{M}$ acromolecular protein complexes have an important role in most cellular processes, e.g., protein transport into cell organells, signal transduction via biological membranes, energy metabolism, directed motion of cells, and cell division. These protein complexes are built of a large number of different proteins, prosthetic groups, coenzymes, and sometimes RNA molecules. Each protein plays a specific role in catalyzing a chemical reaction, stabilization of the protein complex or modulation of the enzyme or complex activity. If only one element of such a multi protein complex is missing, essential parts of the protein complex activity may disappear. To understand the biological function of such a protein complex, a detailed overview of all components must be accessible. In contrast to the easy chemical behavior of simple amino acids, the chemical properties of proteins and peptides vary at least in charge, hydrophobicity, solubility, pI, amino acid composition, and chemical stability (e.g.,

Published online July 24, 2003

Address reprint requests to Dr. A. Sickmann, Protein Mass Spectrometry and Functional Proteomics, Rudolf-Virchow-Center for Experimental Biomedicine, Julius-Maximilians University Wuerzburg, Versbacher Str. 9, Room411,D-97078Wuerzburg,Germany.E-mail:Albert.Sickmann@virchow. uni-wuerzburg.de oxidation, isomerization). Therefore, a global approach for the detection of all peptides derived from a protein mixture seems to be far away even if the different separation and detection techniques have undergone several important improvements during the last few years.

A complete analysis of protein complexes with numerous different components like ribosomes ( $>70$ proteins), centrosomes ( $>100$ proteins) and cell organelles like peroxisomes ( $>300$ proteins) is still an unsolved problem at this time. For a global approach, such an analysis can be done by a high-resolution separation technique, e.g., 2D gel electrophoresis (2D-PAGE), followed by protein identification using mass spectrometry. In 2D-PAGE [1, 2] proteins are separated by their isoelectric points ( $\mathrm{pI}$ ) prior to a common SDS-PAGE separation of molecular weight in the second dimension. This method provides a very high resolution of proteins and a high sensitivity based on different possible protein staining methods [3]. Some disadvantages of 2D-PAGE are that it is a very time-consuming methodology for reproducible protein separation, limitations in protein solubility after isoelectric focusing for hydrophobic proteins (e.g., membrane proteins) [4], partial chemical degradation of basic proteins (e.g., 


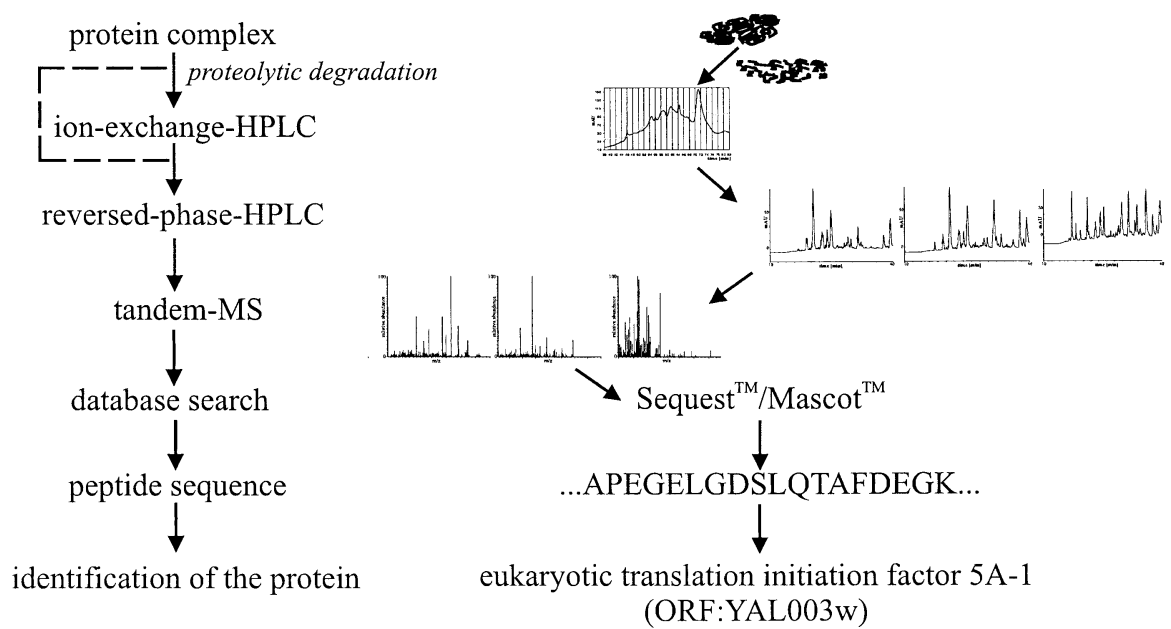

Figure 1. Separation strategy of complex protein mixture. The peptides were either separated via 1D-HPLC (reversed phase chromatography) or by 2D-HPLC (ion exchange chromatography prior to reversed phase chromatography). After separation mass spectrometry was applied and the proteins were identified by the calculated peptide sequence.

DNA binding protein, several membrane proteins) [5], limited molecular weight range (about 7 to $200 \mathrm{kDa}$ ) depending on the poor transfer efficiency of large proteins after isoelectric focussing and the molecular weight separation limit of SDS-PAGE [6].

A further 2D-method to separate intact proteins is a multidimensionalchromatographysystemlikesizeexclusion chromatography (SEC)/reversed phase (RP) followed by mass spectrometry or Edman sequencing [7, 8].

An alternative method for the analysis of protein complexes is the proteolysis of all proteins followed by a multidimensional high resolution liquid chromatography separation (mainly two dimensional) $[9,10]$ and on-line detection of as many different peptides as possible by mass spectrometry. All missing peptides may lead to potential losses of biological informations (e.g., the presence or absence of presequence and PTM's).

Some application examples of this method and its limitations are described in this paper.

\section{Experimental}

\section{Multidimensional Liquid Chromatography, an Overview}

Several different applications of multidimensional chromatography and MS detection have already been described in the literature [11-13]. All results mainly embody a large number of different proteins which could be identified in a protein mixture. In most cases the separation has been done automatically with a "salt step gradient". As no continous increase of the eluting solvent is present between the individual salt steps, the desorption of several peptides from the ion exchange material is incomplete. Therefore, the peptides are distributed in two or more fractions, and at the same time the detection limit is lowered.

Two major applications of salt step gradients are available. The first one is a biphasic column packed with ion exchange and reversed phase material. The sample is applied onto the ion exchange resin, washed, and sequentially eluted with salt steps. This technique was introduced by Washburn et al. [14], as Multidimensional Protein Identification Technology (MudPIT). The second application is an automatic coupling of an ion exchange and a reversed phase column using a dual HPLC valve setup.

As shown by Washburn et al., MudPIT is able to analyze approximately $25 \%$ of the complete yeast proteome (1484 proteins out of ca. 6000 predicted ORFs) within one experiment.

In theory, 6000 proteins result in approximately 60,000-100,000 different proteolytic peptides using a specific protease like trypsin or Glu-C. Approximately two to three times more peptides are generated by unspecific or incomplete digestion at lower concentrations. During a single MudPIT experiment of $24 \mathrm{~h}$, up to 20,000 MS/MS-spectra of sufficient quality can be recorded. The maximum number of identified peptides is limited to the number of different MS/MS-spectra recorded during the experiment. In reality peptides occur as singly, doubly, or triply charged ions which reduce the number of MS/MS-spectra from different peptides by a factor of two or three. Additionally, the variation of the protein expression ratio leads to low and high abundant proteins in each protein sample. The probability to identify more than one peptide from a protein is increased with a higher concentration of the protein. Therefore, it will not be possible to achieve an increase in different proteins from such experiments without faster scanning procedures of the mass spectrometers or increased analysis time. Furthermore, the portion of identified proteins will be lowered if the protein mixture becomes more complex (e.g., proteomes of mammalian cells). 

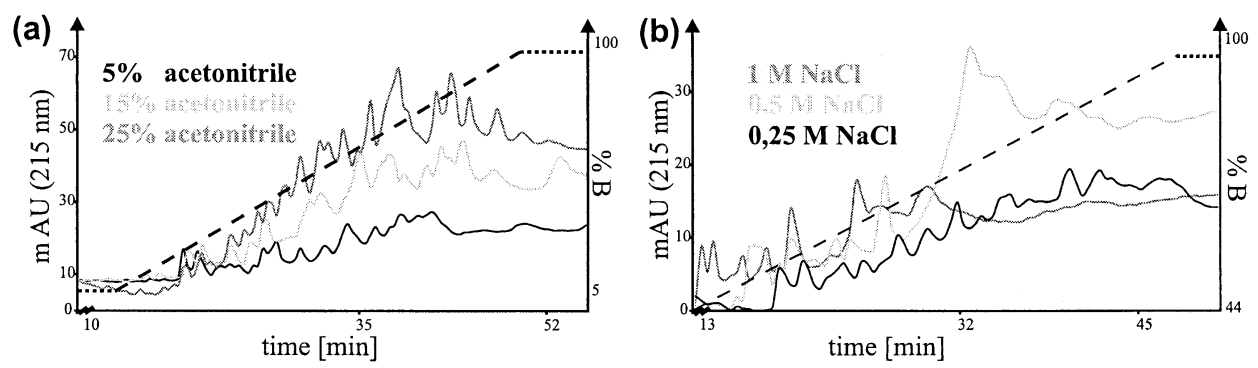

Figure 2. Optimization of the chromatography conditions for cation exchange chromatography. (a) The acetonitrile concentration was varied from 5 to $25 \%$ in buffer B. The best efficiency of the separation was obtained at an acetonitrile concentration of $25 \%(\mathrm{vol} / \mathrm{vol})$ in buffer B. (b) The optimization was accomplished by several different concentrations of $\mathrm{NaCl}$ in buffer $\mathrm{B}$. In the diagram chromatograms with salt concentrations from 1 to $0.25 \mathrm{M} \mathrm{NaCl}$ were shown. The best results were reached at a concentration of $0.25 \mathrm{M} \mathrm{NaCl}$.

An approach to overcome such problems is an offline 2D-HPLC system (Figure 1) to increase the analysis time because the scanning time of the instrument for sufficient MS/MS-spectra is presently limited to approximately one second.

The advantages of an off-line 2D-HPLC system are the application of salt gradients for the peptide elution instead of salt step gradients that cause peak broadening and lower peptide recovery. Although a further separation step includes the risk of partial sample loss this is outweighed by the up to five times (Figure 2) increased peptide recovery by the addition of organic modifier to the eluting solvent. Furthermore, the analysis time can be increased by a factor of four depending on the usage of two and four hour gradients in the second dimension. The disadvantages are the more time consuming sample handling and the lack of automatization during the procedure.

\section{Sample Preparation and In-Solution Digest}

Ribosomes were isolated from yeast (Saccharomyces cerevisiae) microsomes according to Daum and coworkers [15]. The ribosomes were dissolved in $50 \mathrm{mM}$ $\mathrm{NH}_{4} \mathrm{HCO}_{3}$. Trypsin was added [enzyme to protein ratio: 1:20 (wt:wt)] and the solution was incubated over night at $37^{\circ} \mathrm{C}$.

\section{Micro HPLC Separation}

Five $\mu \mathrm{g}$ of tryptic digested ribosomes were separated using a strong anion exchange column $(300 \mu \mathrm{m}$ i.d. $\times$ $150 \mathrm{~mm}$ packed with PL-SAX beads with $1000 \AA$ pore size and $8 \mu \mathrm{m}$ particle size, Dionex, Idstein, Germany) or using a strong cation exchange column $(300 \mu \mathrm{m}$ i.d. $\times 150 \mathrm{~mm}$ packed with PL-SCX beads with 1000 Å pore size and $8 \mu \mathrm{m}$ particle size, Dionex).

For peptide separation the following solvents have been used: anion exchange chromatography, Solution A, $50 \mathrm{mM}$ 2-amino-2-(hydroxymethyl)-1,3-propanediol (tris base), $\mathrm{pH} 8$ versus Solution B, $50 \mathrm{mM}$ 2-amino-2(hydroxymethyl)-1,3-propanediol (tris base), $\mathrm{pH} 8,0.25$
$\mathrm{M} \mathrm{NaCl}, 25 \%$ acetonitrile; for the cation exchange

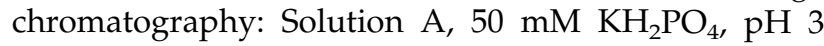
versus solution $\mathrm{B}, 50 \mathrm{mM} \mathrm{KH}_{2} \mathrm{PO}_{4}, \mathrm{pH} 5.5,0.25 \mathrm{M} \mathrm{NaCl}$, $25 \%$ acetonitrile. The gradient started with $5 \%$ Solution $\mathrm{B}$ and rose to $99 \%$ Solution B over a time course of 33 min. The pump (140 B, Applied Biosystems, Foster City, CA) flow was set to $60 \mu \mathrm{L} / \mathrm{min}$ and reduced to a column flow rate of $8 \mu \mathrm{L} / \mathrm{min}$ with a zero death volume T-split. Detection was carried out using a dual channel UV detector (Shimadzu, Tokyo, Japan) equipped with a $35 \mathrm{~nL}$ flow cell (Shimadzu) at $215 \mathrm{~nm}$ (peptide bond) and $295 \mathrm{~nm}$ (tryptophan side chains). Peptide containing fractions were collected manually every minute starting with the gradient.

\section{Nano-HPLC Separation}

Sample preparation for nano-HPLC separation. The fractions were dried down to $5 \mu \mathrm{L}$ and mixed with $10 \mu \mathrm{L}$ $5 \%$ formic acid. The sample was automatically injected into the sample loop using the Famos autosampler (Dionex, Idstein, Germany). The sample volume was reduced to $72 \mathrm{~nL}$ with a precolumn $(0.3 \mathrm{~mm}$ i.d. $\times 1 \mathrm{~mm}$ packed with $\mathrm{C}_{18}$-Pepmap, $100 \AA$ pore size, $3 \mu \mathrm{m}$ particle size) at a flow rate of $40 \mu \mathrm{L} / \mathrm{min} 0.1 \%$ TFA.

Peptide separation. The sample separation was done using the bioinert Ultimate nano-HPLC system (Dionex) running at a column flow-rate of $150 \mathrm{~nL} / \mathrm{min}$. The nano-HPLC separation was done on a $75 \mu$ m i.d. $\times 150$ $\mathrm{mm}$ column (Dionex) packed with reversed phase material $\left(\mathrm{C}_{18}\right.$-PepMap, $100 \AA$ A pore size, $3 \mu \mathrm{m}$ particle size). The gradient (Solution $\mathrm{A}, 0.1 \%$ formic acid versus Solution B, $0.1 \%$ formic acid, $84 \%$ acetonitrile) started at $5 \%$ Solution B and rose to $50 \%$ Solution B in $35 \mathrm{~min}$. Detection was carried out using a dual channel UV detector (Dionex) equipped with a $3 \mathrm{~nL}$ flow cell (Dionex) at 215 and $295 \mathrm{~nm}$.

Peptide detection. LC-MS/MS spectra were recorded on a Finnigan LCQ (Thermo Finnigan, San Jose, CA) ion trap mass spectrometer equipped with a custom-built 
nano-electrospray ion source. The following ESI parameters were used: Spray voltage, $2.0 \mathrm{kV}$; capillary voltage, $42 \mathrm{~V}$; tube lens offset, $30 \mathrm{~V}$; the electron multiplier at $-950 \mathrm{~V}$. No sheath or auxiliary gas was used. The collision energy was set automatically depending on the mass of the parent ion. Trapping time was $200 \mathrm{~ms}$ and the gain control was on. Furthermore, the data was collected in centroid mode and dynamic exclusion was used for data acquisition with exclusion duration of 5 min and an exclusion mass width of $\pm 1.5 \mathrm{Da}$.

\section{Interpretation of the ESI-MS/MS-Spectra}

For the automated database search of fragment ion spectra the SEQUEST [16-18] algorithm (ThermoFinnigan, San Jose, CA, version 27, revision 12) was used. The search parameters were set as follows: Mass tolerance of 1.5 Da for the parent ion, 1.5 Da for fragment ions, tryptic digest, oxidation of methionine as differential modification. The weighting of the different ion series was set to 1 for $b$ - and y-ions. The calculations were carried out on a computer for Proteome Analysis Under Linux Architecture (PAULA). The computer cluster is built of 128 CPUs on 64 nodes. Each node contains $1 \mathrm{~GB}$ of RAM and 80 GB of hard disk space. MS/MS-spectra are searched by one node each. One set of MS/MS datasets (e.g., 1000 MS/MS datasets derived from one LC-ESI-MS/MS run) is handled as a single job. These jobs are distributed automatically to the cluster, or variable partitions of it, in an efficient way to gain maximum performance. A realistic average search time for a single MS/MS-spectrum within the cluster is $150 \mathrm{~ms}$. Therefore, the cluster is able to analyze about 200 million MS/MS-spectra a year.

\section{Results and Discussion}

\section{Separation of Complex Peptide Mixtures Using 2D-HPLC}

To accomplish a multidimensional chromatography, orthogonal systems have to be used for the separation steps. Admittedly, not all chromatography systems are compatible to each other, e.g., in case of too high salt concentration or too high acetonitrile concentration. For our work an ion exchange chromatography in the first dimension and a reversed phase column in the second dimension were coupled off-line to have the possibility to elute in both dimensions with a linear gradient. To increase the number of identified proteins the 2D-HPLC system was optimized, especially regarding the first dimension.

The optimization of reproducible buffer conditions for the ion exchange chromatography was done using a mixture of four proteins (hemoglobine A/B, bovine; myoglobine, horse; $\beta$-lactoglobuline, bovine). For this task a buffer containing $50 \mathrm{mM}$ 2-amino-2-(hydroxymethyl)-1,3-propanediol (tris base) for anion exchange

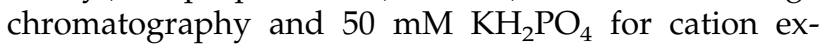

(a)

\begin{tabular}{|l|l|l|l|l}
\hline Full-MS & $\begin{array}{c}\text { Zoom } \\
\text { Spectrum }\end{array}$ & MS/MS & MS/MS & \multicolumn{1}{c}{$t=4 \mathrm{sec}$} \\
\hline \hline Full-MS & MS/MS & MS/MS & MS/MS & MS/MS \\
$t$ & $t=4 \mathrm{sec}$
\end{tabular}

(b)

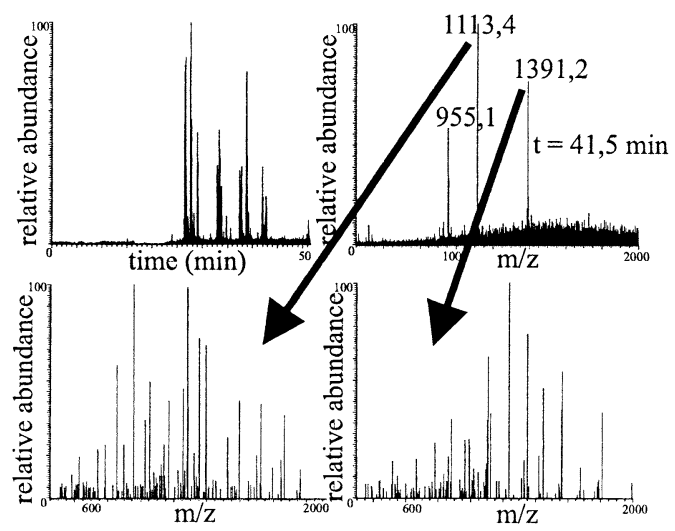

Figure 3. (a) Scheme of the different acquisition methods of the ion trap MS. In our acquisition method no zoom-scan was used but four MS/MS-spectra of different precursor ions were recorded. (b) Example for the new acquisition method. MS/MSspectra of the parent ions at the $m / z$ values at 1113.4 and $1391.2 \mathrm{Da}$ were recorded.

change chromatography was used. Additionally, the buffer system for the cation exchange chromatography contained a $\mathrm{pH}$ gradient ( $\mathrm{pH} 3$ in Buffer $\mathrm{A}, \mathrm{pH} 5.5$ in Buffer B) to enhance the peptide elution from the stationary phase. Since the salt concentration has a strong influence on the performance of the separation, it was varied in the elution buffer.

The selection of the salt concentration in the elution buffer is a balance between sharp peaks, short elution times as well as a large number of coeluting peptides at high salt concentrations and broad peaks, longer elution time as well as reduced number of coeluting peptides at low salt concentration. Furthermore, a low salt concentration is less problematic for the subsequent mass spectrometric detection due to the reduction of peptide complexity and salt adducts causing a strong decrease of the signal intensity. The best results were obtained at a salt concentration of $0.25 \mathrm{M} \mathrm{NaCl}$. However, the usage of further salts like $\mathrm{KCl}$ [19] or $\mathrm{NH}_{4}\left(\mathrm{CH}_{3} \mathrm{COO}\right)$ [20] is described in the literature.

In theory, there is no need for the addition of organic modifier to the elution solution. Nevertheless, acetonitrile in Buffer B (Figure 2) increased the recovery of peptides by a factor of 3 . The addition of acetonitrile is limited to $25 \%$ ( $\mathrm{vol} / \mathrm{vol}$ ) due to a gap in miscibility at $250 \mathrm{mM} \mathrm{NaCl}$ solution. This is the reason why a further increase of acetonitrile in solvent B could not be done.

To increase the number of identified peptides and the sequence coverage of single proteins a new acquisition sequence of the ion trap mass spectrometer was developed and validated (Figures 3 and 4). The manufacturer's presetting of the ion trap instrument is a triple scan event. First was a recording of a full-MS-spectrum followed by a zoom-scan-spectrum and two MS/MS- 

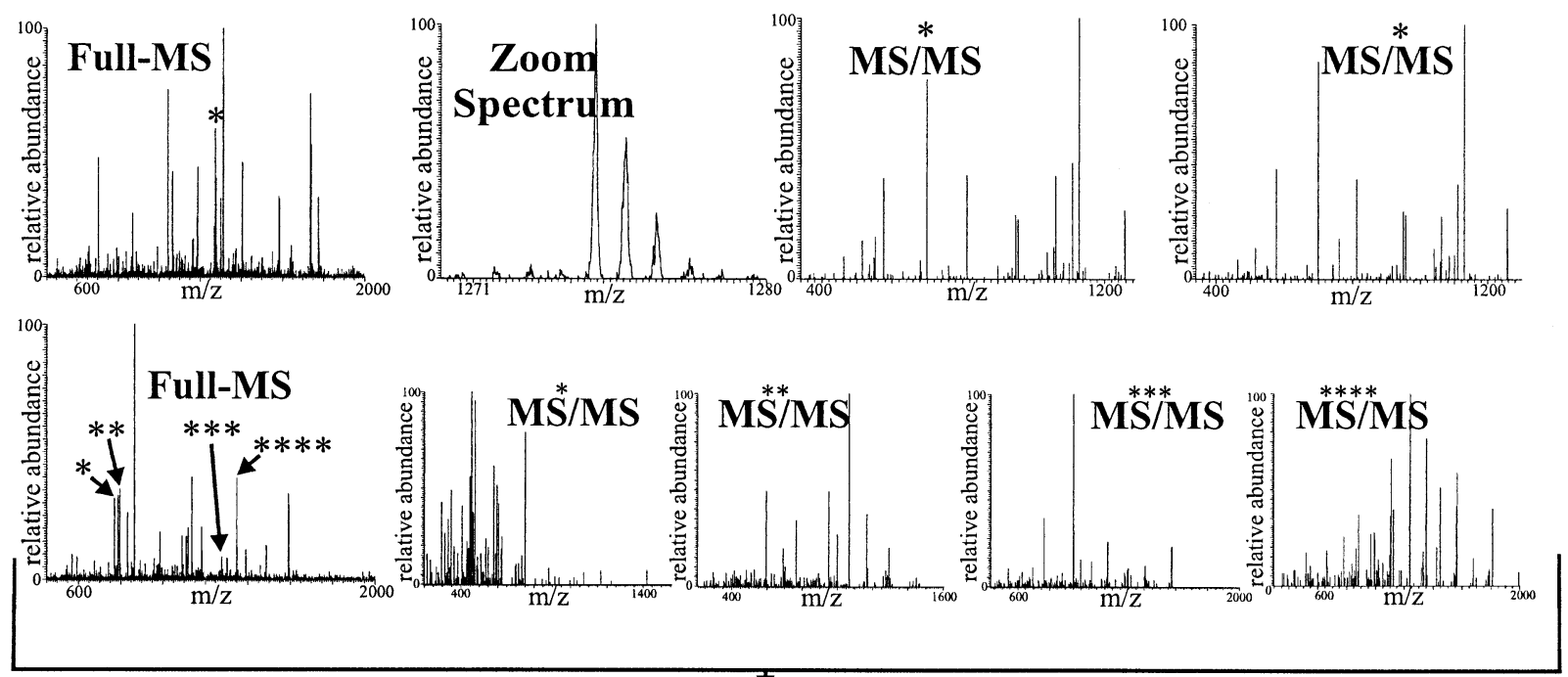

\section{same time}

Figure 4. Comparison of spectra of both acquisition methods. As shown two MS/MS-spectra of the same parent ion needed the same time as four MS/MS-spectra of different parent ions.

spectra of the same precursor ion. In our work no increase in the signal-to-noise-ratio was gained by recording a second MS/MS-spectrum if the first was already of sufficient quality. Considering this fact our sequence included the recording of a full-MS-spectrum followed by four different MS/MS-spectra of the peptides with the most intensive parent ions. The acquisition time was approximately one second per fragmentspectrum of the parent ion.

To compare the two scanning methods the nano-LCMS/MS analysis of $1 \mu \mathrm{g}$ tryptically digested yeast ribosomes was performed. Separations for both methods using a 55 min HPLC gradient and a $110 \mathrm{~min}$ gradient were done three times each for statistical evaluation.

The modified acquisition method showed better sequence coverages and a significant increase in the number of additionally identified proteins by approximately 50\% using the same separation conditions (data not shown). The advantage of this method is evident since the acquisition of MS/MS-spectra for coeluting peptides is four times faster than before. So it will obviously achieve better results at even shorter separation time. The increased gradient time proved to be more efficient than the one hour gradient. Depending on the number of different samples for analysis of a large amount of peptides it is reasonable to separate the peptides with a longer gradient time because better sequence coverages are achieved.

Separation of Tryptically Digested Yeast Ribosomes Using 1D-HPLC and Two Different Systems of $2 D-H P L C$

Besides the comparison of 1D-HPLC and 2D-HPLC the two different ion exchange chromatography methods (anion and cation exchange chromatography) were also compared concerning peptide recovery. Therefore, the tryptically digested ribosomes were separated and analyzed automatically by an ion trap mass spectrometer. For both methods the resolution of the separation was sufficient that a definite variance (Figure 5) of the base peak chromatograms of each rechromatography was observed. In detail, every fraction derived from ion exchange chromatography mainly provided peptides which could not be detected in preceding or following fractions. In comparison to the resolution of an ion exchange chromatography the resolution of a onedimensional reversed phase system was better. Still, several dozens of peptides coeluted during 1D-RPHPLC; therefore, the data dependent precursor fragmentation was only able to select the most abundant peptide ions even when using the four times faster scanning procedure. This function limited the number of the selected precursor ions to the four most intensive ones within the full MS spectrum. In addition to several further identified proteins the 2D-HPLC offered in 76\% of all identified proteins a much better sequence coverage. Nevertheless, some proteins could only be identified by 1D-HPLC separation due to too strong (very hydrophobic peptides) or too weak (very hydrophilic peptides) binding to the stationary phase.

In total, 95 different proteins (Table 1) were detected and identified by 1D- and 2D-LC-MS/MS. It is obvious that more proteins were detected than probably exist in ribosomes due to the fact that other proteins like elongation and initiation factors or chaperones are associated with the ribosomes. Eighteen proteins could be identified only by 1D-HPLC (Figure 6) and 38 with both methods. The remaining 39 proteins could only be separated and analyzed by 2D-HPLC. Nonetheless, a third of all proteins could be represented only by anion 

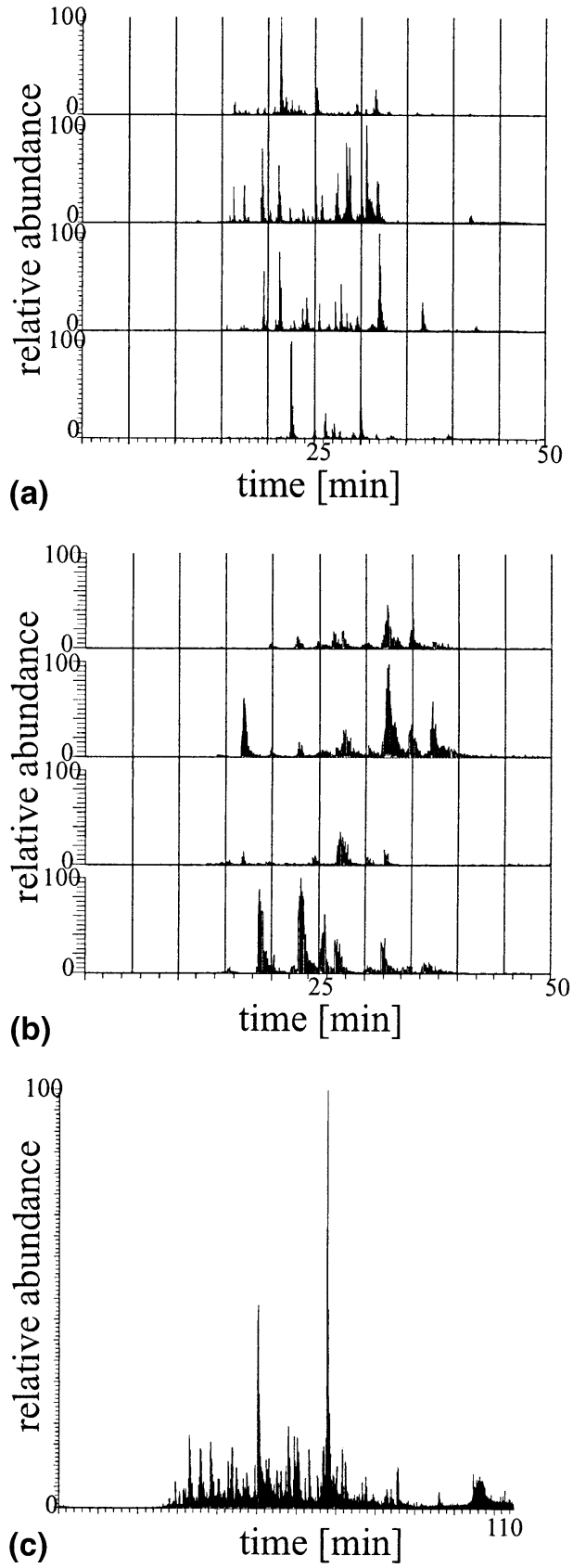

Figure 5. (a) Base-peak-chromatograms of the second dimension of the 2D-HPLC with anion exchange chromatography in the first dimension. To consider the fact of the diversity of the base-peakchromatogram profiles it is obvious that different peptides were eluted in several fractions. (b) Base-peak-chromatograms of the rechromatographies of the previous cation exchange chromatography. The peptide variance of different base-peak-chromatograms was an evidence for the good separation efficiency. (c) Base-peak-chromatograms of the reversed phase chromatography (1D-HPLC). The efficiency of the separation of the 1D-HPLC was not as good as the efficiency of the 2D-HPLCs.

or cation exchange chromatography coupled to reversed phase chromatography. Therefore, the use of only 1D-chromatography and/or 2D-LC, not using cation and anion exchange columns both in the first dimension, would result in the inability to identify all protein components of the analyzed mixture. It is obvious that both 1D-nano-HPLC and 2D-nano-HPLC are necessary to separate and analyze complex mixtures.

\section{Conclusion and Perspectives}

Two-dimensional high performance liquid chromatography (2D-HPLC) is a very efficient method to separate compounds of macromolecular protein complexes like ribosomes. It is a complementary method but cannot replace outright the $1 \mathrm{D}-\mathrm{HPLC}$. The resolution of a multidimensional chromatography is several times better than that of a 1D-RP-HPLC but it is also a more time-consuming method compared to 1D-RP-separation. The data acquisition of one experiment takes two days, the data calculation a further day but the data evaluation several weeks. In comparison to 2D-PAGE, 2D-HPLC handling is easier because of the separation of peptides rather than proteins although no quantification of the peptides without any labeling is possible.

An off-line 2D-HPLC system allows the application of salt gradients with the addition of organic modifier for the peptide elution instead of salt step gradients that cause peak broadening and lower peptide recovery although an off-line system requires a more time consuming sample handling and a lack of automatization during the procedure.

Nevertheless, 2D-HPLC is not an alternative to 2DPAGE but complementary. Indeed, 2D-PAGE remains the superior way to visualize differential protein patterns and protein modifications using several image analysis techniques. As this work points out it is necessary to combine several different kinds of separation techniques to get an almost complete overview of the composition of an easy protein mixture like ribosomes. For this task the presented 1D-HPLC/2D-HPLC system provides good reproducibility and sensitivity. The improvement of buffer conditions for the ion exchange chromatography and the acquisition methods of the ion trap mass spectrometer improved the results of the identifications.

The use of one more separation dimension or prefractionated cell organelles offers a potential for the analysis of more complex protein mixtures, e.g., chloroplasts. Furthermore, it is possible to modify specific amino acids, e.g., methionine, to apply diagonal chromatography. Therefore, two identical chromatographies are performed but a specific modification is introduced between the separations. With this method it would be possible to target defined post-translational modifications [21] like phosphorylations [22, 23].

To apply 2D-HPLC to capillary electrophoresis Issaq et al. $[24,25]$ developed a fraction collector for the first dimension. The concentrated fractions were analyzed simultaneously in the second dimension by a 96-array capillary electrophoresis system. The labeled peptides could thus be detected by laser-induced fluorescence. This offers an alternative to the detection via mass 
Table 1. Summary of all identified proteins of the yeast ribosome

\begin{tabular}{|c|c|c|c|c|c|}
\hline Protein & Gene orf & $\begin{array}{c}\text { Sequence } \\
\text { coverage } \\
\text { in } \%^{a}\end{array}$ & $\begin{array}{c}\text { Identified } \\
\text { with } \\
\text { 1D-HPLC }\end{array}$ & $\begin{array}{l}\text { Identified with 2D-HPLC } \\
\text { (SAX in first dimension) }\end{array}$ & $\begin{array}{l}\text { Identified with 1D-HPLC } \\
\text { (SCX in first dimension) }\end{array}$ \\
\hline$\overline{E F-1}$ & YPR080w & 60.9 & + & + & + \\
\hline EF-2 & YBR118w & 55.4 & + & + & + \\
\hline EF-3 & YLR249w & 34.4 & + & + & + \\
\hline SOA & YGR214w & 27.4 & + & + & \\
\hline S1A & YLR441c & 17.6 & + & & \\
\hline S2 & YGL123w & 26.0 & + & & \\
\hline S3 & YNL178w & 35.0 & + & + & + \\
\hline S4A & YJR145c & 16.5 & & & + \\
\hline S4B & YHR203c & 28.4 & + & + & + \\
\hline S5 & YJR123w & 47.1 & + & + & + \\
\hline S6B & YBR181c & 24.2 & + & & + \\
\hline S7A & YOR096w & 42.1 & + & + & \\
\hline S8B & YER102w & 14.0 & & + & \\
\hline S9A & YPL081w & 8.6 & + & & + \\
\hline S9B & YBR189w & 18.8 & & + & \\
\hline S10A & YOR293w & 14.3 & & & + \\
\hline S10B & YMR230w & 5.7 & & & + \\
\hline S11A & YDR025w & 17.0 & + & & \\
\hline S12 & YOR369c & 14.0 & & + & + \\
\hline S13 & YDR064w & 33.1 & + & + & \\
\hline S14A & YCR031c & 32.8 & + & & + \\
\hline S15 & YOL040c & 52.1 & + & + & + \\
\hline S16A & YMR143w & 62.2 & & + & + \\
\hline S16B & YDL083c & 53.8 & + & & \\
\hline S17A & YMR024w & 57.4 & + & + & + \\
\hline S17B & YDR447c & 27.2 & + & & \\
\hline S18A & YDR450w & 15.8 & & + & \\
\hline S19A & YMR121c & 57.8 & & + & + \\
\hline S19B & YNL302c & 31.9 & + & & \\
\hline $\mathrm{S} 20$ & YHL015w & 43.0 & + & + & + \\
\hline S21A & YKR057w & 15.7 & & + & + \\
\hline S22A & YJL190c & 37.0 & + & & + \\
\hline S22B & YLR367w & 51.5 & + & & \\
\hline S24A & YER074w & 15.6 & & + & \\
\hline S25A & YGR027c & 5.3 & & & + \\
\hline S26B & YER131w & 31.7 & & & + \\
\hline S27A & YKL156w & 18.3 & + & + & \\
\hline S31 & YLR167w & 58.6 & + & + & + \\
\hline L1B & YGL135w & 32.7 & + & & \\
\hline L2A & YBR031w & 55.2 & + & & + \\
\hline L2B & YDR012w & 27.3 & & + & \\
\hline L3 & YOR063w & 24.0 & + & & \\
\hline L4B & YDR012w & 20.2 & & + & \\
\hline L5 & YPL131w & 63.0 & + & + & + \\
\hline L6A & YML073c & 31.3 & + & + & + \\
\hline L6B & YLR448w & 25.0 & & + & \\
\hline L7A & YGL076c & 74.6 & + & + & + \\
\hline L7B & YPL198w & 57.8 & & + & + \\
\hline L8A & YHL033c & 44.2 & + & & + \\
\hline L8B & YLL045c & 56.6 & & & + \\
\hline L9A & YGL147c & 25.7 & + & & + \\
\hline L9B & YNL067w & 25.7 & & + & \\
\hline L10 & YLR075w & 33.9 & + & + & + \\
\hline L11A & YPR102c & 28.4 & & + & \\
\hline L11B & YGR085c & 24.7 & + & & \\
\hline L12B & YDR418w & 43.6 & + & + & + \\
\hline L13A & YDL082w & 41.7 & + & + & + \\
\hline L14B & YHL001w & 26.8 & + & & \\
\hline L15A & YLR029c & 32.3 & & + & + \\
\hline L16A & YIL133c & 31.0 & & + & + \\
\hline \multirow[t]{2}{*}{ L16B } & YNL069c & 24.0 & + & + & + \\
\hline & & & & & (continued \\
\hline
\end{tabular}


Table 1. Summary of all identified proteins of the yeast ribosome ${ }^{a}$

\begin{tabular}{|c|c|c|c|c|c|}
\hline Protein & Gene orf & $\begin{array}{c}\text { Sequence } \\
\text { coverage } \\
\text { in } \%^{\mathrm{a}}\end{array}$ & $\begin{array}{c}\text { Identified } \\
\text { with } \\
\text { 1D-HPLC }\end{array}$ & $\begin{array}{l}\text { Identified with 2D-HPLC } \\
\text { (SAX in first dimension) }\end{array}$ & $\begin{array}{l}\text { Identified with 1D-HPLC } \\
\text { (SCX in first dimension) }\end{array}$ \\
\hline L17A & YKL180w & 44.5 & & + & + \\
\hline L17B & YJL177w & 24.1 & & + & \\
\hline L18A & YOL120c & 23.3 & & + & \\
\hline L19B & YBL027w & 25.9 & + & + & + \\
\hline L20A & YMR242c & 23.3 & + & & + \\
\hline L20B & YOR312c & 18.3 & + & + & \\
\hline L21B & YPL079w & 25.6 & & + & \\
\hline L22B & YFL034c-a & 5.1 & & & + \\
\hline L23A & YBL087c & 37.2 & + & & + \\
\hline L23B & YER117w & 37.0 & + & + & + \\
\hline L24A & YGL031c & 21.9 & + & & \\
\hline L24B & YGR148c & 56.0 & + & + & \\
\hline L25 & YOL127w & 14.5 & & & + \\
\hline L26A & YLR344w & 11.0 & + & & \\
\hline L26B & YGR034w & 26.8 & & + & + \\
\hline L27A & YHR010w & 11.5 & & + & + \\
\hline L27B & YDR471w & 44.1 & + & + & + \\
\hline L28 & YGL103w & 30.9 & + & & \\
\hline L30 & YGL030w & 36.2 & & + & \\
\hline L31A & YDL075w & 37.2 & + & & \\
\hline L32 & YBL092w & 23.1 & + & + & + \\
\hline L36B & YPL249c-a & 38.0 & & & + \\
\hline L38 & YLR325c & 15.9 & & & + \\
\hline L39 & YJL189w & 19.0 & & + & + \\
\hline L40 & YIL148w & 10.8 & & & + \\
\hline L41A & YDL184c & 4.5 & & & + \\
\hline L42A & YNL162w & 3.4 & & & + \\
\hline PO & YLR340w & 47.1 & + & & + \\
\hline P1A & YDL081c & 47.2 & & + & \\
\hline $\mathrm{P} 2 \mathrm{~A}$ & YOL039w & 60.9 & & + & \\
\hline 6-phosphogluconate $\mathrm{DH}$ & YGL025c & 45.4 & + & + & + \\
\hline Hsp70 & YBL075c & 28.7 & + & + & + \\
\hline SUPPRESSOR PROT. MPT4 & YLR150W & 37.4 & + & & \\
\hline EGD1 & YPL037c & 45.2 & + & & \\
\hline elF-5A & YAL003w & 22.0 & & & + \\
\hline
\end{tabular}

aThe given sequence coverage is the total coverage calculated of all methods. The sum of all identified proteins is 95.39 of them were identified by 2D-HPLC only, 38 using 1D-HPLC only. 18 proteins were both detected by 1D- and 2D-HPLC.

(a) Sum of all identified proteins: 95

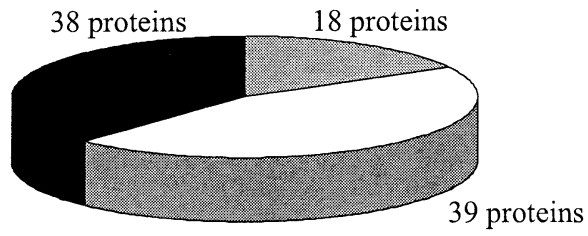

Proteins identified after separation by both $1 \mathrm{D}$ - and 2D-HPLC

Proteins identified after separation by 2D-HPLC only

Proteins identified after separation by 1D-HPLC only (b) Sum of proteins which could be identified by 2D-HPLC: 77

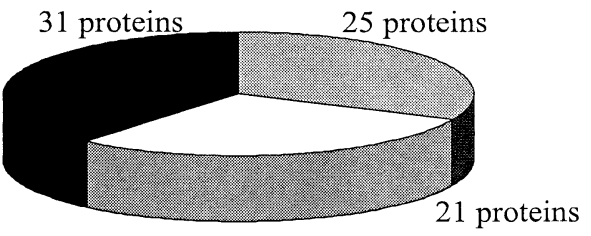

Proteins identified after separation by both cation and anion exchange chromatography Proteins identified after separation by anion exchange chromatography only

Proteins identified after separation by cation exchange chromatography only

Figure 6. (a) Diagram of all identified proteins separated by different chromatography methods before detection. It is necessary to separate the peptide mixture by each applied separation method to get a complete overview of the peptides. (b) Diagram of the identified proteins separated via 2D-HPLC. Anion exchange chromatography as well as cation exchange chromatography was used for first dimension. As shown, it is better to use both approaches in parallel for complete results. 
spectrometry. Furthermore, Unger and co-workers [26] and developed a method for protein mapping by 2DHPLC. An ion exchange column (anion or cation) is coupled automatically to two reversed phase columns in the second dimension. These reversed phase columns are used in parallel, so the analyte fractions from the ion exchange column are transferred alternatively to one of the two reversed phase columns. In comparison to the MudPIT method this method uses a linear gradient system in the first dimension, too. All research groups involved in this field of research cite a variety of advantages of 2D-HPLC, including the ability to analyze low copy number, membrane, highly basic or acidic, or posttranslationally modified proteins. So, the 1D-HPLC/2D-HPLC system presented in this paper offers an excellent separation method for analyzing complex protein mixtures during short analysis time compared to the separation and analysis time of 2DPAGE.

\section{References}

1. O'Farell, P. H. High Resolution Two-Dimensional Electrophoresis of Proteins. J. Biol. Chem. 1975, 250, 4007-4021.

2. Klose, J. Protein Mapping by Combined Isoelectric Focusing and Electrophoresis of Mouse Tissues. A Novel Approach to Testing for Induced Point Mutations in Mammals. Humangenetik 1975, 26, 211-234.

3. Herbert B. Advances in Protein Solubilization for Two-Dimensional Electrophoresis. Electrophoresis 1999, 20(4/5), 660-603.

4. Rabiloud, T.; Adessi, C.; Giraudel, A.; Lunardi, J. Improvement of the Solubilization of Proteins in Two-Dimensional Electrophoresis with Immobilized $\mathrm{pH}$ Gradients. Electrophoresis 1997, 18(3/4), 307-316.

5. Righetti, P. G.; Bossi, A.; Gorg, A.; Obermaier, C.; Boguth, G. Steady-State Two-Dimensional Maps of Very Alkaline Proteins in an Immobilized pH 10-12 Gradient, as Exemplified by Histone Types. J. Biochem. Biophys. Methods 19965; 31 (3/4), 81-91.

6. Harder, A.; Wildgruber, R.; Nawrocki, A.; Fey, S. J.; Larsen, P. M.; Gorg, A. Comparison of Yeast Cell Protein Solubilization Procedures for Two-Dimensional Electrophoresis. Electrophoresis 1999, 20(4/5), 826-829.

7. Opiteck, G. J.; Ramirez, S. M.; Jorgenson, J. W. Moseley, M. A., III. Comprehensive Two-Dimensional High-Performance Liquid Chromatography for the Isolation of Overexpressed Proteins and Proteome Mapping. Anal. Biochem. 1998, 258(2), 349-361.

8. Bushey, M. M.; Jorgenson, J. W. Automated Instrumentation for Comprehensive Two-Dimensional High-Performance Liquid Chromatography of Proteins. Anal. Chem. 1990, 62(2), 161-167.

9. Davis, M. T.; Beierle, J.; Bures, E. T.; McGinley, M. D.; Mort, J.; Robinson, J. H.; Spahr, C. S.; Yu, W.; Luethy, R.; Patterson, S. D. Automated LC-LC-MS-MS Platform Using Binary IonExchange and Gradient Reversed-Phase Chromatography for Improved Proteomic Analyses. J. Chromatogr. B Biomed. Sci. Appl. 2001, 752(2), 281-291.

10. Opiteck, G. J.; Jorgenson, J. W. Moseley, M. A., III;; Anderegg, R. J. Two-Dimensional Microcolumn HPLC Coupled to a
Single-Quadrupole Mass Spectrometer for the Elucidation of Sequence Tags and Peptide Mapping. J. Microcol. Sep. 1998, 10, 365-375.

11. Link, A. J.; Eng, J.; Schieltz, D. M.; Carmack, E.; Mize, G. J.; Morris, D. R.; Garvik, B. M. Yates, J. R., III. Direct Analysis of Protein Complexes Using Mass Spectrometry. Nat. Biotechnol. 1999, 17(7), 676-682.

12. Aebersold, R.; Figeys, D.; Gygi, S.; Corthals, G.; Haynes, P.; Rist, B.; Sherman, J.; Zhang, Y.; Goodlett, D. Towards an Integrated Analytical Technology for the Generation of Multidimensional Protein Expression Maps. J. Protein Chem. 1998, 17(6), 533-535.

13. Ficarro, S. B.; McCleland, M. L.; Stukenberg, P. T.; Burke, D. J.; Ross, M. M.; Shabanowitz, J.; Hunt, D. F.; White, F. M. Phosphoproteome Analysis by Mass Spectrometry and Its Application to Saccharomyces cerevisiae. Nat. Biotechnol. 2002, 20(3), 301-305.

14. Washburn, M. P.; Wolters, D. Yates, J. R., III. Large-Scale Analysis of the Yeast Proteome by Multidimensional Protein Identification Technology. Nat. Biotechnol. 2001, 19(3), 242-247.

15. Zinser, E.; Paltauf, F.; Daum, G. Sterol Composition of Yeast Organelle Membranes and Subcellular Distribution of Enzymes Involved in Sterol Metabolism. J. Bacteriol. 1993, 175(10), 2853-2858.

16. Yates, J. R., III. An Approach to Correlate Tandem Mass Spectral Data of Peptides with Amino Acid sSequences in a Protein Database. Am. Soc. Mass Spectrom. 1994, 5, 976.

17. Yates III, J. R.; Eng, J. K.; McCormack, A. L.; Schieltz D. Method to Correlate Tandem Mass Spectra of Modified Peptides to Amino Acid Sequences in the Protein Database. Anal. Chem.1995, 15; 67 (8), 1426-1436.

18. Yates III, J. R.; Eng, J. K.; McCormack, A. L. Mining Genomes: Correlating Tandem Mass Spectra of Modified and Unmodified Peptides to Sequences in Nucleotide Databases. Anal. Chem. 1995, 15; 67(18), 3202-3210.

19. Andrews, P. C. Ion-Exchange HPLC for Peptide Purification. Peptide Res. 1988, 1(2), 93-99.

20. Careri, M.; Elviri, L.; Mangia, A.; Zagnoni, I. Rapid Method for Determination of Chlormequat Residues in Tomato Products by Ion-Exchange Liquid Chromatography/Electrospray Tandem Mass Spectrometry. Rapid Commun. Mass Spectrom. 2002, 16(19), 1821-1826.

21. Sickmann, A.; Mreyen, M.; Meyer, H. E. Identification of Modified Proteins by Mass Spectrometry. IUBMB Life 2002, 54(2), 51-57.

22. Sickmann, A.; Meyer, H. E. Phosphoamino Acid Analysis. Proteomics 2001, 1(2), 200-206.

23. Kuster, B.; Mann, M. Identifying Proteins and Post-Translational Modifications by Mass Spectrometry. Curr. Opin. Struct. Biol. 1998, 8(3), 393-400.

24. Issaq, H. J.; Chan, K. C.; Janini, G. M.; Muschik, G. M. A Simple Two-Dimensional High Performance Liquid Chromatography/High Performance Capillary Electrophoresis Set-Up for the Separation of Complex Mixtures. Electrophoresis 1999, 20(7), 1533-1537.

25. Issaq, H. J.; Chan, K. C.; Liu, C. S.; Li, Q. Multidimensional High Performance Liquid Chromatography-Capillary Electrophoresis Separation of a Protein Digest: An Update. Electrophoresis 2001, 22(6), 1133-1135.

26. K. Wagner, K. Racaityte, K.K. Unger, T. Miliotis, L. E. Edholm, R. Bischoff, G. Marko-Varga, Protein Mapping by Two-Dimensional High Performance Liquid Chromatography. J. Chromatogr. A 2000, 6; 893(2), 293-305. 